\title{
RHIZOBACTERIA OF SOYBEAN (GLYCINE MAX): IN VITRO SCREENING FOR THEIR PLANT GROWTH PROMOTING POTENTIALS
}

\author{
Bobde Prajakta ${ }^{1},{ }^{2}$, Patil Suvarna ${ }^{1}$ and Rai Alok ${ }^{2^{*}}$ \\ Department of Botany 1, Taywade College, Mahadula-Koradi-441111, Tal.-Kamptee, Dist. Nagpur, \\ Maharashtra, India. \\ Department of Microbiology 2, Seth Kesrimal Porwal College, Kamptee-441001, Dist. Nagpur, \\ Maharashtra, India. \\ Corresponding author: alok.rrai@gmail.com
}

\section{ABSTRACT:}

Plant growth promoting rhizobacteria (PGPR) are the rhizosphere bacteria that may be utilized to augment plant growth and suppress plant diseases (Shaikhul Islam et al.2016). In the search for efficient PGPR strains associated to the Soybean (Glycine max), a total of 95 isolates were obtained from the rhizospheric soil of soybean plants that were grown in the agricultural fields of Kamptee region. Among 95 isolates, 12 isolates were selected based on their in vitro antagonism towards phytopathogens. The effective antagonists were further screened for their plant growth promoting (PGP) activities viz., Phosphate solubilizing assay, Zinc solubilizing assay, Potassium solubilizing assay, Ammonia production, HCN production, Nitrogen fixation, Siderophore production, IAA production, and Chitinase assay. 11 isolates were positive for phosphate solubilization on Pikovskaya agar, 3 isolates were able to solubilize zinc, all 12 isolates were positive for ammonia, $\mathrm{HCN}$ and IAA production, 8 isolates were able to fix atmospheric nitrogen, of total twelve isolates, the only isolate unable to grow in chitin media was PB-5, rest all the eleven isolates were positive for chitinase assay, and 7 isolates found positive for siderophore production. Since these PGPR inoculants exhibited multiple positive PGP traits beneficial to the host plants, they may be applied in the development of new, safe, and effective bio-inoculants for improving plant growth and yield.

Keywords: rhizobacteria, phytopathogens, Pikovskaya agar and siderophore.

\section{INTRODUCTION:}

The rhizosphere is the rich source of microbes and microbial activity and thus better known as a storehouse of microbes and it consists of a large number of microorganisms mainly bacteria. These bacteria can be symbiotic or non-symbiotic on the basis that not only the plants get benefitted by their presence but bacteria also derive the nutrients for their survival (Kundan et al. 2015). Among these potential soil microorganisms, the most promising bacteria are known as plant growth promoting rhizobacteria (PGPR). In this sense, PGPR may be used to enhance plant health and promote plant growth rate without environmental contamination (Calvo et al. 2014). Soybean is an important Kharif oilseed crop in Maharashtra. Soybean is gaining popularity on account of its unique characteristics and adaptability to varied agro-climatic conditions. However, due to the extreme diversity of pathogens and serious diseases severe plant losses and yield reductions are common in susceptible cultivars of the soybean (Zivkovic V. et al., 2010). Rhizoctonia solani is one of the most important soil-borne fungal pathogens, which develops both in cultured and non-cultured soils, causing diseases in different crops. Damping-off of seedlings is the most common disease caused by $R$. solani. It has a wide host range and causes diseases in a variety of crops such as potato, tomato, cucumber and soybean.

Hence, the present study was designed to isolate and characterize bacteria from the rhizosphere of soybean plants having PGP and antagonistic traits so that they can be exploited as a potential bioinoculants for soybean.

\section{METHOD AND MATERIAL:}

The study site and soil sampling: The soil samples used in the present study for the isolation of rhizospheric bacterial spp. were collected from soybean cultivating farms of 5 different villages of Kamptee region (Nagpur) in Maharashtra, India. The location of the site is at $21.20^{\circ} \mathrm{N}$ latitude and $79.18^{0}$ E longitude with an elevation of $284 \mathrm{~m}$. The root adhering samples of soybean plants were collected from randomly selected soybean crop under each 
cultivar in sterile plastic bags and immediately transported to the lab for the further process (Zarrin Fatima, 2009).

Isolation of Bacteria: The plant growth promoting rhizobacteria were isolated from the rhizosphere soil sample by serial dilution plate method (Ghevariya K.K., et al., 2014). One gm of soil was homogenized in $9 \mathrm{ml}$ of sterilized distilled water and incubated at room temperature (RT) for 5 minutes. Serial dilution was done in the distilled water up to $10^{-8}$ and $500 \mu l$ of different dilute sample were spread on different isolation agar plates viz. actinomycetes isolation agar, pseudomonas isolation agar, oatmeal agar, nutrient agar and ISP-2 medium. Plates were incubated at $28 \pm 2{ }^{\circ} \mathrm{C}$ in $\mathrm{BOD}$ incubator for $24 \mathrm{hr}$ and observed for the bacterial growth. Colonies were picked from these plates on the basis of different morphotypes and maintained as a pure culture in respective media with periodic transfer to fresh media and stocked for further use.

SCREENING OF POTENTIAL ISOLATES
THROUGH CHARACTERIZATION OF PLANT
GROWTH PROMOTING (PGP) PROPERTIES
Phosphate solubilising assay:
solubilizing activity was assessed on pikovskaya's agar plates by measuring the clear zone surrounding the developed bacterial colony, after 7 days of incubation at $30^{\circ} \mathrm{C}$ (Pikovskaya, 1948).

Zinc solubilising assay: All the isolates were inoculated on to the modified Pikovskaya medium containing $1 \%$ insoluble zinc compound $(\mathrm{ZnO})$. All the plates were incubated for $48 \mathrm{hr}$ at $28^{\circ} \mathrm{C}$. The halo zone around the colony was measured and considered as Zinc solubilizing bacteria (Ghevariya K.K., 2014).

Potassium solubilising assay: All the isolates were spot inoculated on to the Aleksandrov agar medium. All the plates were incubated for 3 days at $30^{\circ} \mathrm{C}$. The halo zone around the colony was measured and considered as potassium solubilising bacteria (Ghevariya K.K., 2014).

Ammonia production: For the analysis of the production of ammonia the $18-20 \mathrm{hr}$ old broth cultures were observed for the development of yellow to orange colour after addition of Nesslers reagent (Dye, 1962).
HCN production: The production of $\mathrm{HCN}$ was determined by the procedure given by (Gajbhiye A., et al., 2010).

Nitrogen- Fixing Activity: The Nitrogen-Fixing Activity was determined by the procedure given by (Khin Mya Lwin, 2012).

Siderophore production test: Siderophore production was tested qualitatively using chromeazurol $\mathrm{S}$ medium (CAS medium) (Sharma and Johri, 2003).

Qualitative assay of Indole acetic acid (IAA): The selected antagonistic bacterial strains were grown in $5 \mathrm{ml}$ of nutrient broth medium in a test tube for 24 hrs. After an incubation period, bacterial culture was harvested and centrifuged at 10,000xg for $15 \mathrm{~min}$ at $4^{\circ} \mathrm{C}$. Two drops of orthophosphoric acid were added to $2 \mathrm{ml}$ of cell-free supernatant and the development of colour was observed the presence of a pink colour indicate positive reaction for indole acetic acid (IAA) and yellow colour indicate negative reaction (Reetha S., 2014).

Qualitative assay of Chitinase: The qualitative assay for chitinase production was performed according to the method described by Marten et al. (2000). The $24 \mathrm{hr}$ old culture of the Bacillus spp. on the nutrient agar slants was spot inoculated by single streak on the chitin medium, the plates were incubated at $30^{\circ} \mathrm{C}$ for $24 \mathrm{hrs}$, then $0.1 \%$ congo red solution was fed over the plates and clear halos around and beneath the growth indicating the enzymatic degradation was observed and measured after 5 to 14 days.

\section{RESULT AND DISCUSSION:}

Bacterial isolation: A total of 95 bacterial strains were obtained from the rhizosphere of soybean (Table-1). Among 95 isolates, 12 isolates (PB 2, PB 5, РВ 7, РB 28, РB 31, РВ 35, РВ 36, РВ 37, РВ 42, PB 43, PB 10 and PB 20) were selected based on their in vitro antagonism towards phytopathogen $(R$. solani) (Fig. 1g-h), on the basis of morphological and biochemical test and plant growth promoting attributes. All the 12 PGPR were found to belong to Bacillus genera. However, due to the vastness of the data, we provide here only the details of the 12 
promising isolates with multiple PGP traits (Table$1)$.

Plant growth promoting activities: Out of 12 isolates, 11 isolates showed phosphate solubilization except one PB 43 (Table-1, Fig.1e) and 3 isolates showed zinc solubilization (Table-1, Fig.1d), whereas all the 12 isolates were found negative for potassium solubilizing activity. However, all isolates showed IAA (Table-1, Fig-1a), HCN production (Table-1, Fig1c) and Ammonia production (Table-1, Fig-1b), while, 8 isolates were positive for Nitrogen fixation. By using CAS agar medium, out of 12 isolates, there were 7 isolates found positive for siderophore production (Table-1, Fig-1g). These strains were also tested positive for catalase and oxidase activity of which 12 isolates showed the most important activity of IAA and chitinase assay (Table-1). These results indicate some strains have the potential for plant growth promotion via inhibition of specific groups of deleterious bacteria, but none of the test strains has a strong potential for indirect plant growth promotion via inhibition of fungal plant pathogens. In contrast to the results from this study, authors (Jayaraj et al., 2005; Karimi et al., 2012; Patil et al., 2014) reported strong inhibition of fungi and oomycetes by strains of $B$. subtilis. The different results suggest that antimicrobial activity varies among Bacillus species and strains.

\section{CONCLUSION:}

These studies concluded that the twelve chosen isolates of Bacillus genera viz., PB 2, PB 5, PB 7, PB 28, PB 31, PB 35, PB 36, PB 37, PB 42, PB 43, РB 10 and $\mathrm{PB} 20$ which were positive for maximum PGP traits have proven to be most promising and can be selected as effective PGPR strains. All the isolates were reported as potential PGPR with best activities and they were further characterized by $16 \mathrm{~S}$ rDNA sequencing (data not shown) as Bacillus spp. The experiment performed under in vitro condition has 2 major conclusions:

i.) Out of 45, 12 isolates were found positive for all the plant growth promoting potentials. Such multiple positive PGP traits isolates can be further explored as potential biofertilizers for the sustainable agriculture.

ii.) The direct promotion of plant growth by PGPR include facilitating the uptake of certain nutrients like nitrogen, phosphorus, zinc and potassium in accessible form for nutrient availability from the soil and root environment by producing plant hormone indole-3-acetic acid.

With the success story of this primary screening protocol, we can further move on to their assessment under field conditions which might be useful for the development of potential inoculants / biofertilizer for increasing the growth and productivity of soybean plants.

Acknowledgment: We are thankful to University Grants Commission (UGC), New Delhi for providing partial financial support under the Major Research Project F. No. 41-1177/2012 (SR).

\section{REFERANCE :}

Calvo, P., Nelson, L.M., and Kloepper, J.W., (2014): Agricultural uses of plant biostimulants. Plant Soil, 383, 3-41.

Dye, D.W., (1962): The inadequacy of the usual determinative tests for identification of Xanthomonas spp. NZT Sci., 5, pp. 393-416.

Gajbhiye, A., Rai, A.R., Meshram, S.U. et al. World J Microbiol Biotechnol (2010) 26: 1187. https://doi.org/10.1007/s11274-009-0287-9.

Ghevariya K.K. and Desai P.B. (2014): Rhizobacteria of sugarcane: In vitro screening for their plant Growth Promoting potentials. Research Journal of Recent Sciences. ISSN 2277-2502 Vol. 3, 5258.

Jayaraj, J., Radhakrishnan, N. V., Kannan, R., Sakthivel, K., Suganya, D., Venkatesan, S., and Velazhahan, R. (2005): Development of new formulations of Bacillus subtilis for management of tomato damping-off caused by Pythium aphanidermatum. Biocontrol Science and Technology, 15(1), 55-65. 
Karimi, K., Amini, J., Harighi, B., and Bahramnejad, B. (2012): Evaluation of biocontrol potential of 'Pseudomonas' and 'Bacillus' spp. against Fusarium wilt of chickpea. Australian Journal of Crop Science, 6(4), 695.

Khin Mya Lwin, Moe Moe Myint, Tar Tar, and Wai Zin Moe Aung, (2012): Isolation of Plant Hormone (Indole-3-Acetic Acid -IAA) Producing Rhizobacteria and Study on their Effects on Maize Seedling. ENGINEERING JOURNAL Volume 16 Issue 5, DOI:10.4186/ej.2012.16.5.137.

Kundan Rishi, Garima Pant, Nitesh Jadon and Pavan Kumar Agrawal (2015): Plant Growth Promoting Rhizobacteria: Mechanism and Current Prospective. J Fertil Pestic, 6:2 DOI: 10.4172/2471-2728.1000155.

Martens H. and Schweigel M. (2000): Grass tetany and other hypomagnesaemias. In Veterinary Clinics of North America: Food Animal Practice: Metabolic Disorders of Ruminants, vol. 16, pp. 339-368 [T Herdt, editor]. Philadelphia, OPA: Saunders.

Patil, S., Bheemaraddi, C. M., Shivannavar, T. C., and Gaddad, M. S. (2014): Biocontrol activity of siderophore producing Bacillus subtilis CTSG24 against wilt and dry root rot causing fungi in chickpea. IOSR J Agric Vet Sci, 7(9), 63-8.

Pikovaskya R.I. (1948): Mobilization of phosphorus in soil in connection with the vital activity of some microbial species. Microbiology, 7, 362370 .

Reetha S., Bhuvaneswari G., Thamizhiniyan P., Mycin T.R. (2014): Isolation of Indole Acetic Acid (IAA) Producing Rhizobacteria of Pseudomonas fluorescens and Bacillus subtilis and Enhance Growth of Onion (Allim cepa L.). Int J Curr Microbiol App Sci; 3: 568-574.

Sharma, A., Johri, B. N., Sharma, A. K., and Glick, B. R. (2003): Plant growth-promoting bacterium Pseudomonas $s p$. strain GRP3 influences iron acquisition in mung bean (Vigna radiata L. Wilzeck). Soil Biol. Biochem. 38, 887-894.
Zarrin Fatima, M. Saleemi, Muhammad Zia, T. Sultan, M. Aslam, Riaz -Ur-Rehman and M. Fayyaz Chaudhary (2009): Antifungal activity of plant growth-promoting rhizobacteria isolates against Rhizoctonia solani in wheat. African Journal of Biotechnology Vol. 8 (2), pp. 219-225, ISSN 1684-5315 (C) 2009 Academic Journals.

Zivkovic V, Stojanovic Z, Ivanovic. Z, et al. (2010): Screening of antagonistic activity of microorganisms against Colletotrichum acutatum and Colletotrichum gloeosporioides; Arch. Biol. Sci. 62(3):611-623. 


\section{PHOTOPLATE-I}

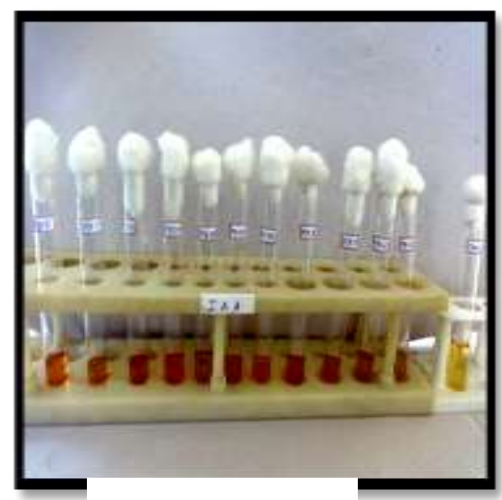

(a)

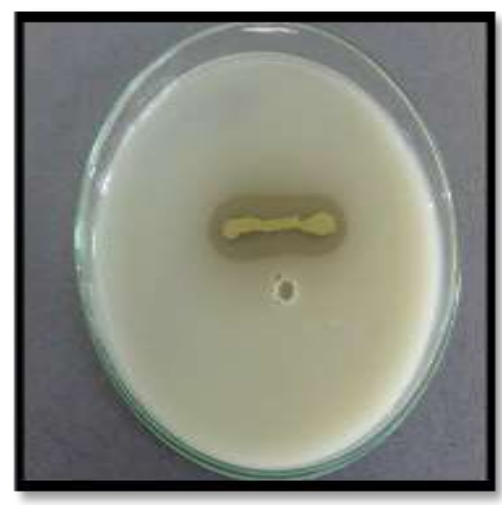

(d)

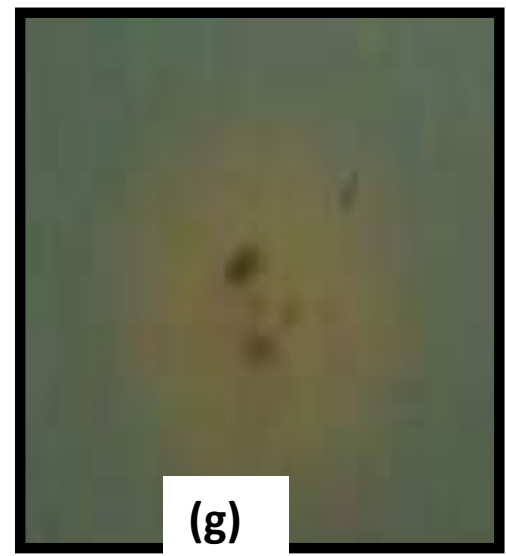

(g)

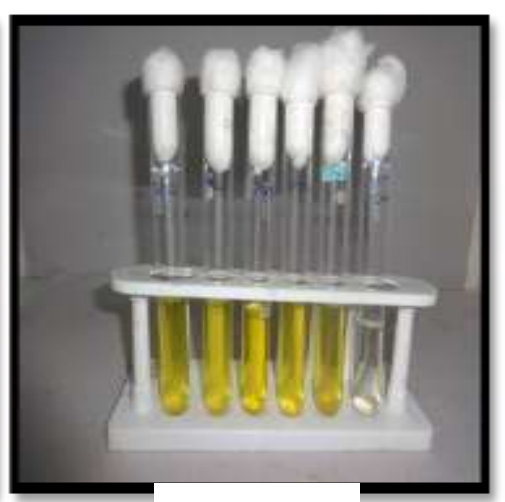

(b)

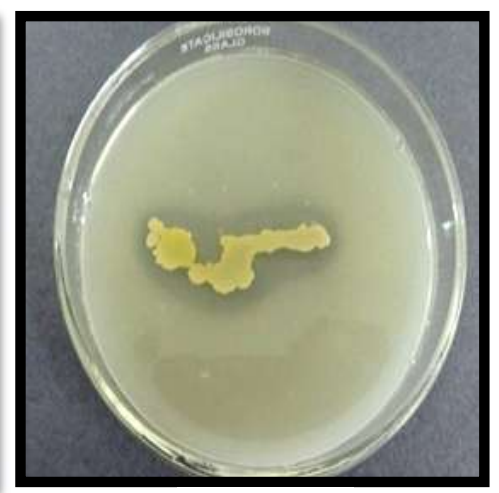

(e)

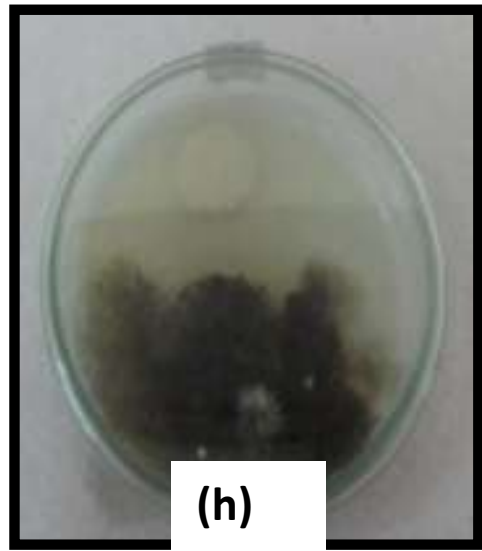

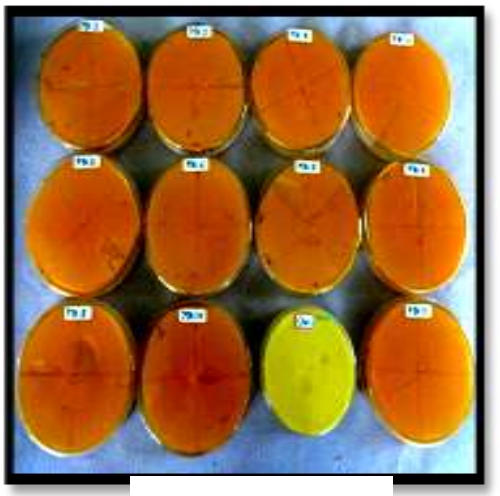

(c)

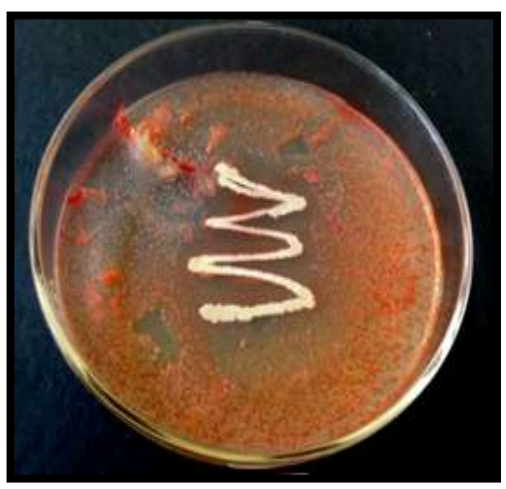

(f)

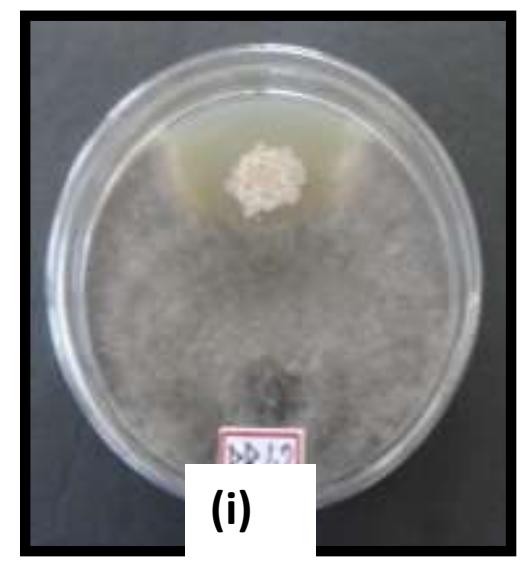

Figure-1 (a) Indole acetic acid production (b) Ammonia production (c) HCN production (d) Zinc solubilizing bacteria (e) Phosphate solubilizing bacteria (f) Chitinase assay (g) Siderophore production (h-i) In vitro antagonistic activity of bacteria against $R$. solani. 